\title{
Development of a clinically adoptable joint coordinate system for the wrist
}

\author{
Submitted as a Full-Length Article
}

Oluwalogbon O Akinnola, MEng ${ }^{1}$

Vasiliki Vardakastani, $\mathrm{PhD}^{1}$

Angela E Kedgley, $\mathrm{PhD}^{1 *}$

${ }^{1}$ Department of Bioengineering, Imperial College London, London, United Kingdom

Email addresses:

OOA: o.akinnola16@imperial.ac.uk

VV:v.vardakastani13@imperial.ac.uk

AEK: akedgley@imperial.ac.uk

* Corresponding author:

Angela E Kedgley

Department of Bioengineering

Imperial College London

South Kensington Campus

London SW7 2AZ

Phone: +44 (0) 2075940747 


\begin{abstract}
Kinematics play a vital role in answering both clinical and research questions regarding joint biomechanics. Standardisation of kinematic approaches is important; however, the method that is currently recommended for building the joint coordinate system (JCS) to measure kinematics of the wrist is difficult to implement in vivo. In this study, a series of JCSs were examined and compared to the International Society of Biomechanics (ISB) recommendations in terms of landmark digitisation repeatability, coordinate frame creation repeatability, and secondary rotations during planar motion. No differences were found between the ISB JCS and 338 of 408 of the JCSs proposed in the study, meaning that the proposed alternative can be used without affecting the measured joint angles or repeatability of the JCS. Forearm frames that used a vector between the epicondyles to define the YZ plane of the forearm were found to create JCSs that produced secondary rotations greater than that which would be clinically detectable and thus, they should be avoided when defining a JCS. The remaining 338 coordinate systems can be used interchangeably; consequently, should there be any clinical limitations that result in missing landmarks, alternative coordinate systems can be used.
\end{abstract}

A joint coordinate system created using the radial styloid, ulnar styloid, medial epicondyle, lateral epicondyle, the heads of the second and fifth metacarpal, and the base of the third metacarpal is recommended for quantifying kinematics in vivo.

Keywords: joint coordinate system, wrist, coordinate frame, hand, forearm 


\section{Introduction}

Changes in the kinematics of the wrist are used to diagnose injury or pathology (Garcia-Elias, 1999; Moritomo et al., 2008) and alterations in kinematics can indicate the severity of a condition (Kitay and Wolfe, 2012). Furthermore, kinematics are used to define research questions (Lucareli et al., 2007) and serve as both inputs and a means of validation for musculoskeletal models (Eschweiler et al., 2016; Goislard De Monsabert et al., 2018). Thus, it is important that the measurement of wrist kinematics is reliable and consistent across studies, so that results can be compared. Inconsistencies in joint coordinate system (JCS) definitions inhibit cross-study comparison and the ability to verify and implement research conclusions in clinical practice. Without a consistent reference, it is not possible to attribute differences to anatomical factors, as they may be due to mathematics. The importance of consistency in the measurement of kinematics was recognised by the International Society of Biomechanics (ISB) with the publication of recommendations for building coordinate systems to measure joint kinematics (Wu et al., 2005, 2002), inspired by a JCS developed by Grood and Suntay (1983). Specifically, these recommendations followed the paradigm of being readily interpretable by clinicians. However, the ISB recommendations were developed using cadaveric studies and thus use landmarks that are not easily observable in vivo, without the use of imaging. For example, in the hand, the formation of the $x$-axis of the third metacarpal coordinate frame, which points palmarly, forms a plane that splits the metacarpal into mirror images. This makes the recommendations difficult to implement in a clinical setting, which has led to the development of alternative approaches (Hillstrom et al., 2014; Kraszewski et al., 2015). Ideally, JCSs used to measure kinematics should be implementable in both research and clinical scenarios.

The aim of this study was to develop a wrist JCS that could be applied easily to in vivo and in vitro studies whilst still performing as well as, and providing comparable outputs to, the ISB recommended JCS. 


\section{Materials and methods}

\subsection{Experimental design}

An eight-camera motion capture system (Oqus 500+ cameras, $<0.5 \mathrm{~mm}$ error, Qualisys, Gothenburg, Sweden) was used to record the wrist and forearm motion of 23 participants, 10 male $(1.76 \pm 0.07 \mathrm{~m} ; 76.4 \pm 12.9 \mathrm{~kg})$ and 13 female $(1.67 \pm 0.07 \mathrm{~m} ; 62.0 \pm 9.2 \mathrm{~kg})$. Each participant performed unrestrained wrist flexion-extension (FE), radioulnar deviation (RUD), and forearm pronation-supination (PS) at a self-selected speed. Each motion was repeated 15 times, divided into three sets of five cycles. 14 palpable landmarks (Figure 1, Table 1) of the hand and forearm were digitised twice. The motions were performed unguided at a selfselected speed and participants were instructed to go through as full a range of motion as was comfortable. The landmarks of the hand were digitised with the hand clenched into a fist, the forearm pronated, and the hand and forearm lying fully prone on the table. The forearm landmarks were digitised with the elbow on the table, the forearm supinated, and the hand positioned vertically above the elbow.

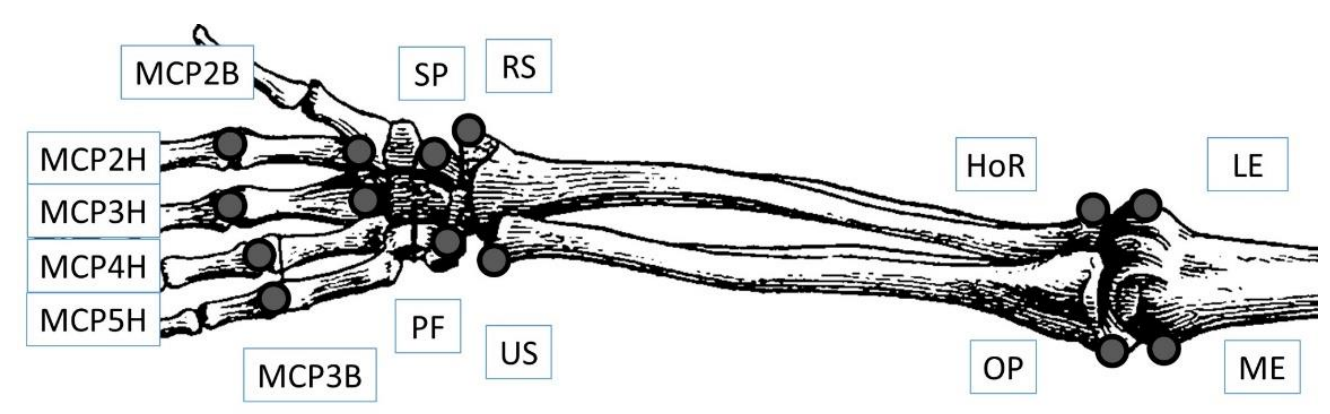

Figure 1: Palpated landmarks: heads of the 2nd-5th metacarpals (MCP2H-5H), bases of the 2nd \& 3rd metacarpals (MCP2B, 3B), scaphoid process (SP), pisiform (PF), radial styloid (RS), ulnar styloid (US), head of radius (HoR), olecranon process (OP), medial epicondyle (ME), lateral epicondyle (LE). Adapted from May (1890). 
Table 1. The 14 hand and forearm anatomical landmarks that were twice digitised to build the joint coordinate systems investigated in this study.

\begin{tabular}{|c|c|c|c|}
\hline Landmark & Location & $\begin{array}{c}\text { Landmark } \\
\text { Code }\end{array}$ & $\begin{array}{l}\text { Associated } \\
\text { Coordinate Frame }\end{array}$ \\
\hline Lateral epicondyle & $\begin{array}{l}\text { Lateral-most protrusion of the epicondyle } \\
\text { on the proximal end. The landmark will } \\
\text { begin to curve inwards were you to } \\
\text { palpate any further proximally. }\end{array}$ & LE & Forearm \\
\hline Medial epicondyle & $\begin{array}{l}\text { Medial-most protrusion of the epicondyle } \\
\text { on the proximal end. The landmark will } \\
\text { begin to curve inwards were you to } \\
\text { palpate any further proximally. }\end{array}$ & $\mathrm{ME}$ & Forearm \\
\hline $\begin{array}{l}\text { Ulnar head (olecranon } \\
\text { process) }\end{array}$ & $\begin{array}{l}\text { Proximal- and dorsal-most point of the } \\
\text { process. The landmark will begin to slope } \\
\text { away were you to palpate any further in } \\
\text { any direction. }\end{array}$ & $\mathrm{OP}$ & Forearm \\
\hline Radial head & $\begin{array}{l}\text { Proximal-most point of the radius, just } \\
\text { distal to the radial-humeral joint. The } \\
\text { landmark will very quickly dip into the } \\
\text { joint were you to palpate any further } \\
\text { proximally. }\end{array}$ & HoR & Forearm \\
\hline Radial styloid & $\begin{array}{l}\text { Lateral-most protrusion of the styloid on } \\
\text { the distal end. The landmark will begin to } \\
\text { curve inwards were you to palpate any } \\
\text { further distally. }\end{array}$ & RS & Forearm \\
\hline Ulnar styloid & $\begin{array}{l}\text { The medial-most protrusion of the styloid } \\
\text { on the distal end. The landmark will begin } \\
\text { to curve inwards were you to palpate any } \\
\text { further distally. }\end{array}$ & US & Forearm \\
\hline $5^{\text {th }}$ metacarpal head & $\begin{array}{l}\text { Distal-most point of the metacarpal, just } \\
\text { proximal to the curvature of the head. }\end{array}$ & MCP5H & Hand \\
\hline $4^{\text {th }}$ metacarpal head & $\begin{array}{l}\text { Distal-most point of the metacarpal, just } \\
\text { proximal to the curvature of the head. }\end{array}$ & MCP4H & Hand \\
\hline $3^{\text {rd }}$ metacarpal base & $\begin{array}{l}\text { Proximal-most past of the metacarpal, just } \\
\text { distal to the metacarpal-carpus joint. }\end{array}$ & МСР3В & Hand \\
\hline $3^{\text {rd }}$ metacarpal head & $\begin{array}{l}\text { Distal-most point of the metacarpal, just } \\
\text { proximal to the curvature of the head. }\end{array}$ & МСР3H & Hand \\
\hline $2^{\text {nd }}$ metacarpal base & $\begin{array}{l}\text { Proximal-most point of the metacarpal, } \\
\text { just distal to the metacarpal-carpus joint. }\end{array}$ & MCP2B & Hand \\
\hline $2^{\text {nd }}$ metacarpal head & $\begin{array}{l}\text { Distal-most point of the metacarpal, just } \\
\text { proximal to the curvature of the head. }\end{array}$ & $\mathrm{MCP} 2 \mathrm{H}$ & Hand \\
\hline Pisiform & $\begin{array}{l}\text { Palmar-most point of the pisiform on the } \\
\text { proximal and lateral side. The landmark } \\
\text { will curve away should you palpate any } \\
\text { further proximally or laterally. }\end{array}$ & PS & Hand \\
\hline Scaphoid process & $\begin{array}{l}\text { Palmar-most point of the scaphoid } \\
\text { process on the proximal and radial side. } \\
\text { The landmark will curve away should you } \\
\text { palpate any further proximally or radially. }\end{array}$ & SP & Hand \\
\hline
\end{tabular}




\subsection{Data processing}

Groupings of the landmark digitisations were used to build 17 forearm (F1 - F17) and 24 hand $(\mathrm{H} 1-\mathrm{H} 24)$ coordinate frames (Appendix A). Though there were differences in the definitions of the JCSs, all of the axes pointed in the same general direction. Namely, the X-axis pointed dorsally, the Y-axis pointed proximally, and the Z-axis pointed radially. Where possible, the coordinate frames were built according to approaches documented in the literature (Kraszewski et al., 2015; Murgia et al., 2004) and by adapting the ISB recommendations (Wu et al., 2005). F1 and $\mathrm{H} 1$ were built according to the ISB recommendations specifically (Wu et al., 2005, Table 2). JCSs were created by combining each forearm frame with each hand frame. A Cardan sequence of $Z X Y$ was used to calculate the joint angles from the rotation matrices.

Table 2. Recommendations for segment coordinate system definitions according to the International Society of Biomechanics (Wu et al., 2005).

\begin{tabular}{|l|l|l|l|l|}
\hline $\begin{array}{l}\text { Segment } \\
\text { Coordinate System }\end{array}$ & Y axis & X axis & Origin \\
\hline F1 & $\begin{array}{l}\text { Vector from ulnar } \\
\text { styloid to midpoint } \\
\text { of medial and } \\
\text { lateral epicondyles }\end{array}$ & $\begin{array}{l}\text { Cross product } \\
\text { between y-axis and } \\
\text { vector from ulnar } \\
\text { styloid to radial } \\
\text { styloid }\end{array}$ & $\begin{array}{l}\text { Cross product } \\
\text { between X and Y } \\
\text { axes }\end{array}$ & Ulnar styloid \\
\hline $\mathrm{H} 1$ & $\begin{array}{l}\text { Vector from base } \\
\text { of third metacarpal } \\
\text { to head of third } \\
\text { metacarpal }\end{array}$ & $\begin{array}{l}\text { Cross product } \\
\text { between y-axis and } \\
\text { vector from head } \\
\text { of second } \\
\text { metacarpal to third } \\
\text { metacarpal }\end{array}$ & $\begin{array}{l}\text { Cross product } \\
\text { between X and } \mathrm{Y}\end{array}$ & axes \\
\hline
\end{tabular}

\subsection{Data analysis}

A statistical power test was performed based on the repeatability of digitisation of the epicondyles in (Schwartz et al., 2011); the recommended sample size was 20 people. Two metrics were used to assess the coordinate frames. The repeatability of the landmark digitisations, quantified as the magnitude of the vector between the two digitisations of each landmark, averaged across the participants, was used to assess their quality. The repeatability of the creation of the axes 
of each coordinate frame was calculated as the angular difference between the axes formed from the two sets of digitisations. The magnitude of the secondary rotations during planar motions was used to compare the JCSs. Secondary rotations were defined as rotations about the axes other than that describing the primary degree of freedom (DoF) of the motion, i.e. RUD and PS were secondary rotations during FE. These were quantified by plotting the angles of rotation normalised by time. The data were rectified and integrated to give the area under each curve. The secondary rotation curves for all JCSs were compared individually and areas under them were also summed together and normalised by the area under primary rotation curve to give a quantitative measure of the secondary rotations of each JCS.

The repeatability of the landmarks and frame axes were compared using analysis of variance (ANOVA). The repeatability of the axes was also tested using the Kruskal-Wallis test. Significance for both was defined as $p<0.05$. Post-hoc analysis was done using Tukey's honestly significant difference criterion. For each of the three sets of five cycles of motion, the kinematic data of cycles two through four were time and amplitude normalised to test for differences using statistical parameter mapping (SPM). As cycles one and five featured the start and the end of the motions, they were omitted from the comparisons to reduce variability in the kinematics. SPM is an application of random field theory used to make statistical inferences about data that are continuous in space or time (Friston, 2007). The SPM technique allows for comparisons accounting for the overall pattern of the kinematic data. Kinematics defined using each of the JCSs were compared to those quantified using the ISB JCS. Differences in the primary rotation were recorded as a joint angle difference (JAD); SPM ANOVA was used to test for differences in the JADs, with an SPM t-test used for post-hoc analysis. Significance was defined as $p<0.05$ with a Bonferroni correction.

\section{Results}

ANOVA testing indicated a significant difference in the repeatability of the forearm landmarks $(p=0.008)$. Post-hoc testing showed that the ulnar styloid was more repeatable than the head of the radius $(p<0.001)$. There were no other differences in the repeatability of the landmarks $(p>0.185$, Figure 2 ), nor the repeatability of the axes (ANOVA, $p>0.3 ;$ Kruskal-Wallis, $Z, p>$ 
0.3) (Figure 3). Thus, the head of the radius was the least repeatable landmark to palpate on the forearm, so should be avoided.

The JCS built from the combination of $\mathrm{F} 10$ and $\mathrm{H} 23$ (Appendix A) produced normalised secondary rotations of 0.35 (Appendix B) and F8 and H14 (Appendix A) produced normalised secondary rotations of 0.90 (Appendix B). However, neither were statistically different from other combinations $(p>0.80)$. The forearm frames F8 and F17 were found to have JADs in the secondary DoFs of up to $30^{\circ}$ during FE and up to $25^{\circ}$ during RUD. These JADs were greatest when the aforementioned coordinate frames were combined with hand frame H16. No statistical differences were found in the JADs in the primary DoF between each of the 408 JCSs relative to the ISB JCS $(p>0.05)$.

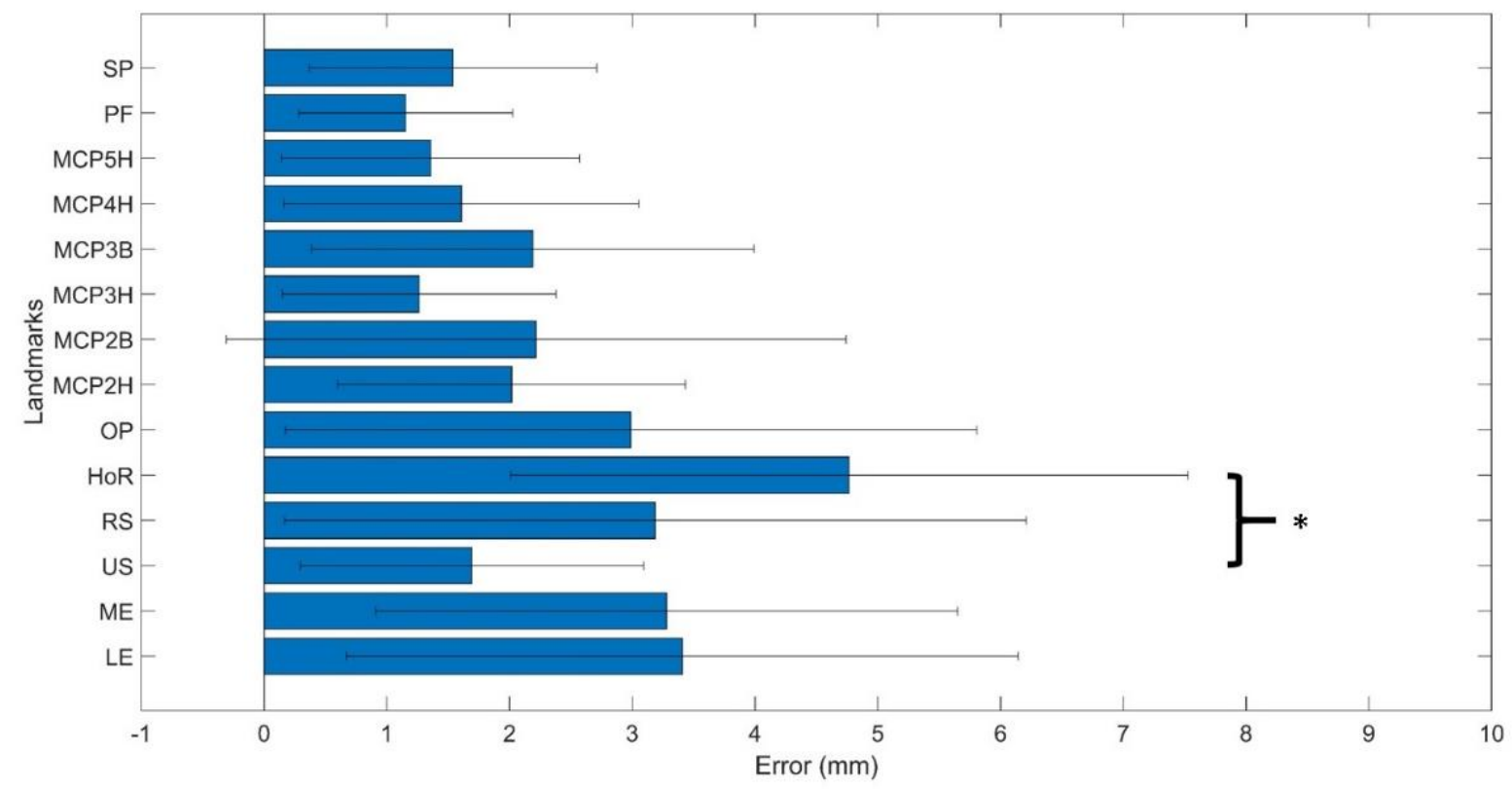

Figure 2: Mean \pm one standard deviation of the digitisation repeatability for the scaphoid process (SP), pisiform (PF), head of the fifth metacarpal (MCP5H), head of the fourth metacarpal (MCP4H), base of the third metacarpal (МCP3B), head of the third metacarpal $(\mathrm{MCP} 3 \mathrm{H})$, base of the second metacarpal (MCP2B), head of the second metacarpal (MCP2H), olecranon process (OP), head of the radius (HoR), radial styloid (RS), ulnar styloid (US), medial epicondyle (ME), and lateral epicondyle (LE) across the population. Repeatability was defined as the magnitude of the vector between two digitisations of each landmark, a larger value indicating a less repeatable landmark. Significant difference is indicated with an asterisk. 


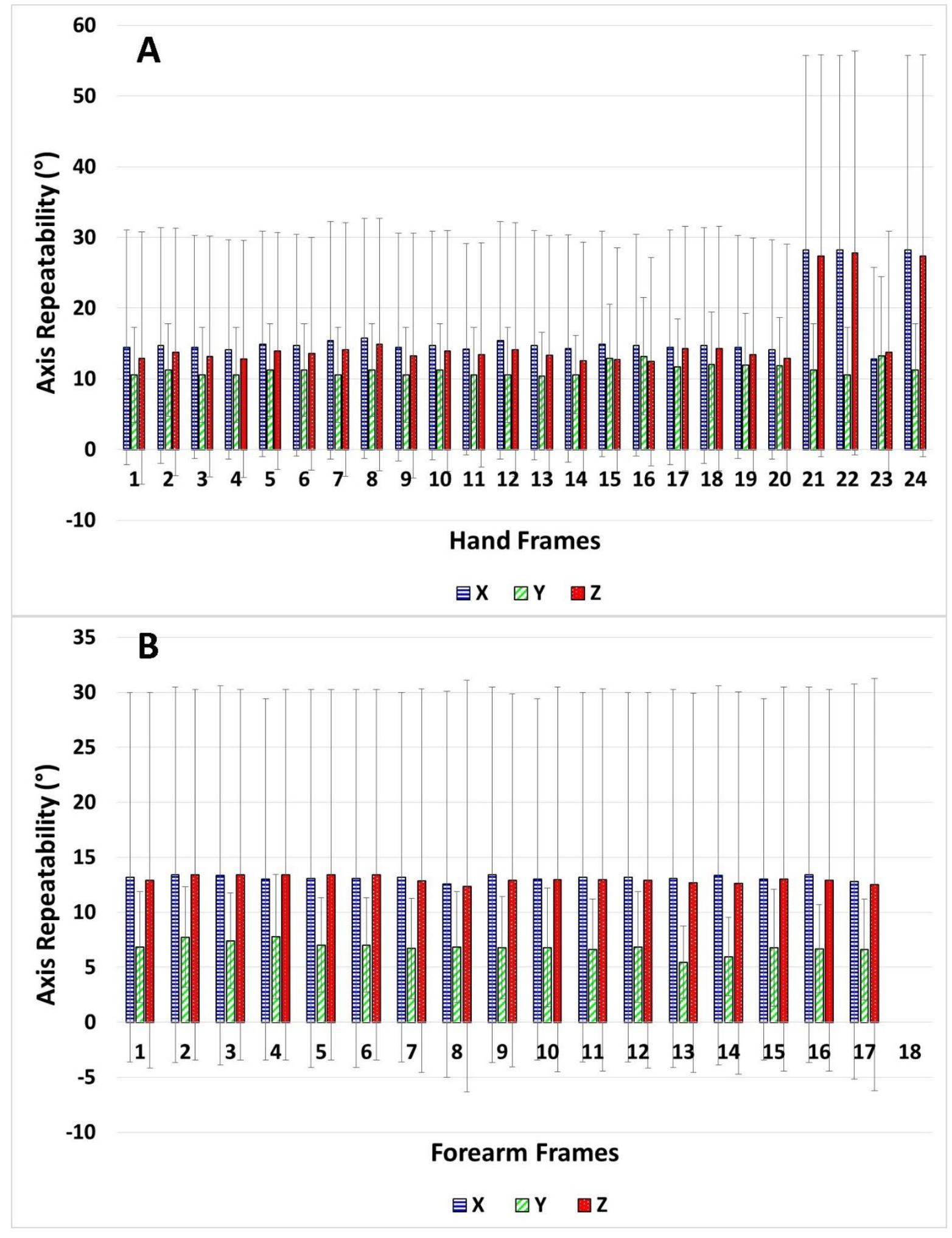

Figure 3: Mean \pm one standard deviation of the repeatability of the $X, Y$, and $Z$ axes of the alternate definitions of the $(A)$ hand and $(B)$ forearm anatomical coordinate frames. 
A JCS created by expressing hand frame $\mathrm{H} 14$ with respect to forearm frame $\mathrm{F} 11$ is recommended, as it both minimises the secondary rotations and maximises the repeatability of the segment frame axes. These frames use landmarks as far apart as possible to minimise sensitivity to differences in landmark digitisation. No statistical differences were found between the primary rotation joint angles measured in the ISB JCS and the recommended JCS; the kinematics recorded using the recommended frame were as repeatable as when recorded using the ISB JCS (Figure 4), and the differences in the primary and secondary joint angles between the ISB and the recommended JCS were less than $3.1^{\circ} \pm 1.9^{\circ}$ (Figure 5).
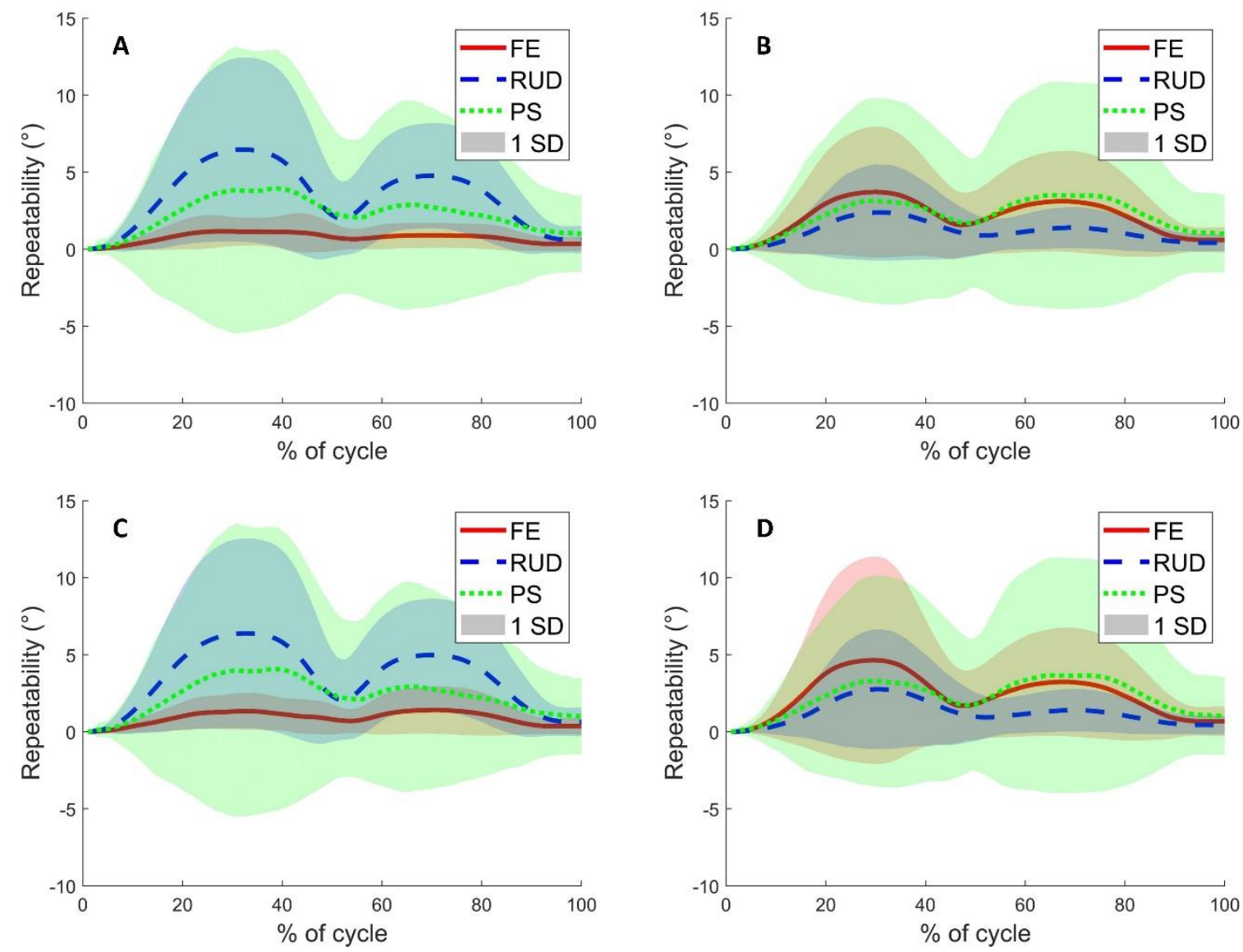

Figure 4: Mean \pm one standard deviation (SD) of the kinematic differences in flexionextension (FE), radioulnar deviation (RUD), and pronation-supination (PS) resulting from two sets of digitisations built using ( $\&$ \& ) the ISB joint coordinate system and (C \& D) the recommended joint coordinate system. The differences during nine repetitions were averaged for all 23 participants performing (A \& C) FE and (B \& D) RUD. 

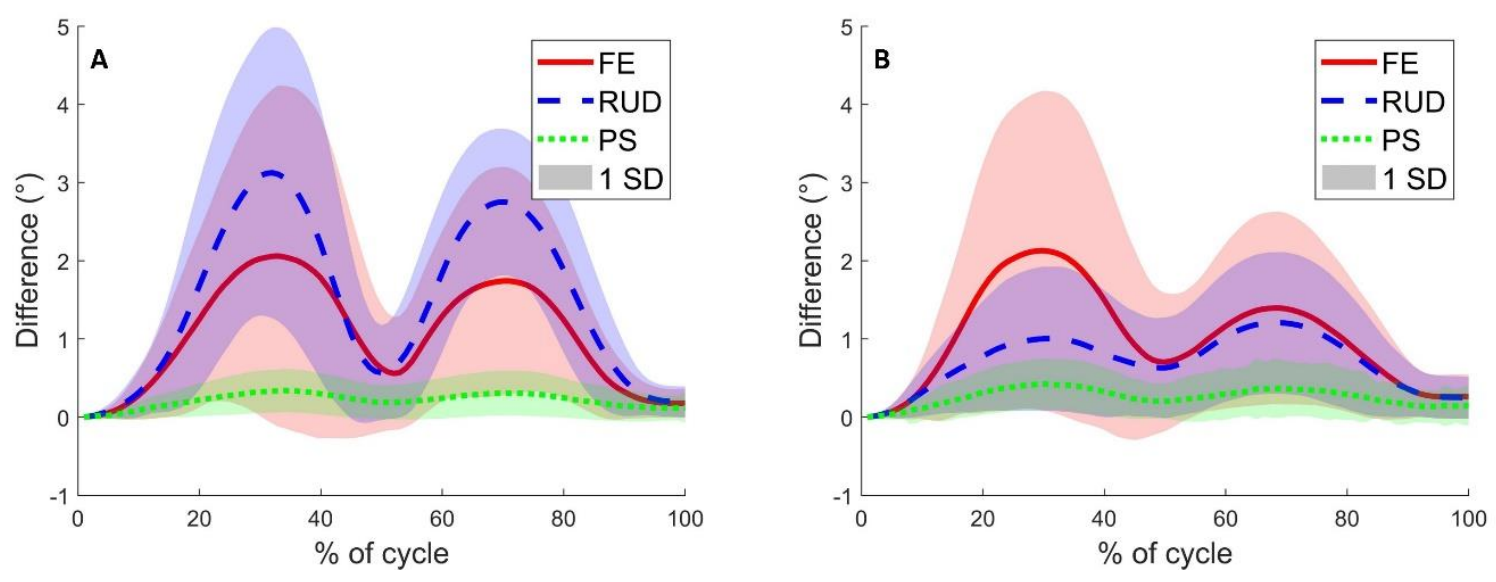

Figure 5: Mean \pm one standard deviation (SD) of the kinematic differences in flexionextension (FE), radioulnar deviation (RUD), and pronation-supination (PS) between the recommended joint coordinate system and the ISB joint coordinate system for all participants during (A) FE and (B) RUD.

\section{Discussion}

The data presented showed no differences between $83 \%$ of the JCSs proposed in this study and that recommended by the ISB. The only difference in landmark digitisation repeatability was between the ulnar styloid and the head of the radius (Figure 2), suggesting that the head of the radius not be used in defining a JCS. There were no differences between the repeatability of the $X, Y$, and $Z$ axes of the hand and forearm coordinate frames (Figure 3 ). These findings suggest that repeatability does not need to be the primary consideration when selecting between the segment-based coordinate frames investigated in this study, as they were all similarly repeatable when being digitised by a single investigator.

As with the repeatability, the secondary rotations estimated by the JCSs were similar. The combination of $\mathrm{F} 10$ and $\mathrm{H} 23$ was found to minimise the secondary rotations during $\mathrm{FE}$ whereas F8 and $\mathrm{H} 14$ minimised the secondary rotations during RUD. This agrees with previous findings that the two motions are not orthogonal (Akinnola et al., 2020). Out of plane rotations are to be expected, but minimising secondary rotations has the benefit of making joint angles easier to interpret, which is one of the reasons the Grood and Suntay (1983) system was adopted. However, forearm frames F8 and F17 and hand frame $\mathrm{H} 16$ resulted in JADs in the secondary DoFs that would be clinically detectable (Carter et al., 2009; Reissner 
et al., 2019). Investigating the definition of these coordinate frames provides potential explanations for this. Both F8 and F17 use the epicondyles instead of the styloids to form a vector that, along with the $\mathrm{Y}$-axis of the frame, defines the $\mathrm{X}$-axis. The results suggest that the vector between the epicondyles is skew to the $\mathrm{Z}$ axis of the forearm and, thus, using it to define the YZ plane results in differences in kinematics that would be clinically detectable. In creating $\mathrm{H} 16$, the $\mathrm{Y}$-axis points from the midpoint between the $2^{\text {nd }}$ and $5^{\text {th }}$ metacarpal heads to the base of the second metacarpal. Again, it is likely that this vector is sufficiently skew to the $\mathrm{Y}$-axis in the ISB definition of the hand frame to result in clinically detectable changes in the kinematics. Omitting JCSs involving these frames leaves 338 JCSs (83\%) with kinematics comparable to the ISB JCS. Considering all the metrics in this study, F11 (Equation 1) and H14 (Equation 2) are recommended for creating a JCS of the wrist. This combination produces small secondary rotations during FE and RUD, its axes are as repeatable as the ISB recommended system, and it results in kinematics that are neither clinically nor statistically different from kinematics measured in the ISB JCS. This JCS uses only palpable landmarks of the upper limb, so can be used in vivo without necessitating imaging.

$$
\begin{aligned}
& P 1=\frac{L E-M E}{2} \\
& P 2=\frac{R S-U S}{2} \\
& V=\overrightarrow{U S R S} \\
& Y=\frac{\overrightarrow{P 2 P 1}}{\| \overrightarrow{P 2 P 1 \|}} \\
& X=\frac{Y \times V}{\|Y \times V\|} \\
& Z=\frac{X \times Y}{\|X \times Y\|} \\
& O=U S \\
& V=\frac{M C P 2 H-M C P 5 H}{2} \\
& P 3=\frac{M C P 5 H M C P 2 H}{M S} \\
& V=
\end{aligned}
$$




$$
\begin{aligned}
& Y=\frac{\overrightarrow{P 3 M C P B} B}{\|\overrightarrow{P 3 M C P 3 B}\|} \\
& X=\frac{Y \times V}{\|Y \times V\|} \\
& Z=\frac{X \times Y}{\|X \times Y\|} \\
& O=\frac{Y}{2}
\end{aligned}
$$

Where:

- $\quad \mathrm{P} 1, \mathrm{P} 2$, and P3 are the positions of temporary points to build the coordinate frames;

- $\quad \mathrm{V}$ is a temporary vector used to build the coordinate frame;

- $X, Y$, and $Z$ are the vectors that define the axes of the coordinate frame;

- $\mathrm{O}$ is the vector describing the position of the origin of the coordinate frame;

- US (ulnar styloid), RS (radial styloid), ME (medial epicondyle), LE (lateral epicondyle), $\mathrm{MCP} 2 \mathrm{H}$ (head of the second metacarpal), MCP3B (base of the third metacarpal), $\mathrm{MCP} 5 \mathrm{H}$ (head of the fifth metacarpal) are locations of the palpated landmarks (Figure1, Table1).

Whilst this study recommends a JCS to encourage standardisation, the presented results suggest that the majority of the suggested coordinate frames could be used without statistically different results. Kinematic differences that would be detectable clinically were only found in two of the forearm frames and one of the hand frames. This means that, provided investigators avoid using the epicondyles to define the YZ plane of the forearm, the kinematic results from studies that have used different wrist JCSs are comparable. Thus, concerns about comparing results between studies are ameliorated. This also means that in clinical situations where landmarks are unavailable or difficult to palpate, such as partial amputation or development of Bouchard nodes, an alternative frame could be used without significantly changing the derived kinematics.

A limitation of this study was the absence of a gold standard, such as medical imaging, with which to compare the digitisation of the landmarks on the skin with digitising them on the bone. In addition, previous literature has found that investigator experience has a substantial influence on repeatability of palpation (Schwartz et al., 2011) and only one investigator 
performed the digitisations in this study. Thus, the repeatability of the landmark digitisations are indicative, but not necessarily definitive. The repeatabilities of landmark palpation in this study were, however, comparable to those presented by de Groot (1997; ME: 3.4 mm, LE: 3.4 $\mathrm{mm}$ ) and more repeatable than Schwartz et al. (2011; ME: $8.7 \mathrm{~mm}$, LE: $7.2 \mathrm{~mm}$ ).

It is expected that the repeatability of landmark palpation will affect the repeatability of the coordinate frame axes, which in turn affect the repeatability of the kinematics. Consequently, it would seem odd for the repeatability of the kinematics to be superior to that of the axes. However, it is important to note that the repeatability of the axes is the angular difference between axes formed from two digitisations and the repeatability of the kinematics is the difference in the relative rotation of the hand frame with respect to the forearm frame between two digitisation sets. Two sets of axes could have a large angular difference between them, and this would result in low axis repeatability. Nonetheless, if the axes of the hand and forearm frame from the second digitisation deviate by a similar amount relative to the first digitisation set of axes, and crucially in the same direction, then the kinematic repeatability will be higher. Skin motion artefact between digitisations could result in landmarks shifting relative to the clusters. This would result in the hand and forearm frames shifting in the same direction.

A potential reason for not obtaining a statistical difference in the repeatability of the coordinate frames axes was that the number of participants was similar to the number of coordinate frames being compared. This could have affected the performance of the ANOVA parametric test and masked significant differences. To account for such an error, an appropriate non-parametric test was employed. In addition, previous research has found similar results to those presented in this manuscript, namely no significance in the secondary rotations during FE and similarly that the primary DoF JAD would not be clinically detectable (Padmore et al., 2020). However, Padmore et al. (2020) reported significant differences in the secondary rotations during RUD which was not found in this work. In addition, the list of JCSS investigated in this study was not exhaustive. Further research could investigate a more definitions of JCSs to create a comprehensive set of recommendations on what to avoid when building a JCS. 


\section{Conclusion}

This study proposes a joint coordinate system of the wrist created using readily palpable landmarks, thus averting the need for imaging to identify landmarks for in vivo applications. It was found to perform minimise secondary rotations, making the result easily interpretable, and joint angles did not differ from those calculated using the ISB recommended system. Thus, it can be readily employed in both clinical and research scenarios. The data indicate that there are no differences between the majority of the joint coordinate systems investigated in this study. Along with the recommended JCS, it is advised that investigators do not use a vector between the epicondyles to define the YZ plane of the forearm coordinate frame. The data suggest that kinematics can be compared between published findings using different coordinate systems, and alternative coordinate systems may be used should there be clinical limitations to the availability of anatomical landmarks.

\section{Conflict of interest statement}

The authors have no conflicts of interest to declare.

\section{References}

Akinnola, O.O., Vardakastani, V., Kedgley, A. E. 2020. The effect of planar constraint on the definition of the wrist axes of rotation. J. Biomech. 113, 110083. In Press.

https://doi.org/10.1016/j.jbiomech.2020.110083

Carter, T.I., Pansy, B., Wolff, A.L., Hillstrom, H.J., Backus, S.I., Lenhoff, M., Wolfe, S.W., 2009. Accuracy and Reliability of Three Different Techniques for Manual Goniometry for Wrist Motion: A Cadaveric Study. J. Hand Surg. 34, 1422-1428.

https://doi.org/10.1016/j.jhsa.2009.06.002

de Groot, J.H., 1997. The variability of shoulder motions recorded by means of palpation. Clin. Biomech. 12, 461-472. https://doi.org/10.1016/S0268-0033(97)00031-4

Eschweiler, J., Stromps, J.-P., Fischer, M., Schick, F., Rath, B., Pallua, N., Radermacher, K., 2016. Development of a biomechanical model of the wrist joint for patient-specific model guided surgical therapy planning: Part 1. Proc. Inst. Mech. Eng. [H] 230, 310-325. https://doi.org/10.1177/0954411916632791 
Friston, K. 2007. Statistical parametric mapping. In: Friston, K., Ashburner, J., Kiebel, S., Nichols, T., Penny, W. (Eds.), Statistical Parametric Mapping. Academic Press, London, pp. 10-31. https://doi.org/10.1016/B978-012372560-8/50002-4

Garcia-Elias, M., 1999. Position Statement: Definition of Carpal Instability: The Anatomy and Biomechanics Committee of the International Federation of Societies for Surgery of the Hand2. J. Hand Surg. 24, 866-867. https://doi.org/10.1053/jhsu.1999.0866

Goislard De Monsabert, B., Edwards, D., Shah, D., Kedgley, A., 2018. Importance of Consistent Datasets in Musculoskeletal Modelling: A Study of the Hand and Wrist. Ann. Biomed. Eng. 46, 71-85. https://doi.org/10.1007/s10439-017-1936-z

Grood, E.S., Suntay, W.J., 1983. A Joint Coordinate System for the Clinical Description of Three-Dimensional Motions: Application to the Knee. J. Biomech. Eng. 105, 136-144. https://doi.org/10.1115/1.3138397

Hillstrom, H.J., Garg, R., Kraszewski, A., Lenhoff, M., Carter, T., Backus, S.I., Wolff, A., Syrkin, G., Cheng, R., Wolfe, S.W., 2014. Development of an anatomical wrist joint coordinate system to quantify motion during functional tasks. J. Appl. Biomech. 30, 586-593. https://doi.org/10.1123/jab.2011-0094

Kitay, A., Wolfe, S.W., 2012. Scapholunate Instability: Current Concepts in Diagnosis and Management. J. Hand Surg. 37, 2175-2196. https://doi.org/10.1016/j.jhsa.2012.07.035

Kraszewski, A.P., Osei, D.A., Garg, R., Jang, E., Hillstrom, H.J., Lenhoff, M.W., Wolfe, S.W., 2015. The effect of wrist surgery on the kinematic consistency of joint axis reconstruction in a static posture. J. Orthop. Res. 33, 1341-1347. https://doi.org/10.1002/jor.22912

Lucareli, P.R.G., Lima, M. de O., Lucarelli, J.G. de A., Lima, F.P.S., 2007. Changes in joint kinematics in children with cerebral palsy while walking with and without a floor reaction ankle-foot orthosis. Clin. Sao Paulo Braz. 62, 63-68. https://doi.org/10.1590/s180759322007000100010

May, C.H., 1890. Anatomy, Physiology and Hygiene, With Special Reference to the Effects of Stimulants and Narcotics, for Use in Primary and Intermediate Schools. New York, W. Wood and Company.

Moritomo, H., Murase, T., Oka, K., Tanaka, H., Yoshikawa, H., Sugamoto, K., 2008. Relationship Between the Fracture Location and the Kinematic Pattern in Scaphoid Nonunion. J. Hand Surg. 33, 1459-1468. https://doi.org/10.1016/j.jhsa.2008.05.035

Murgia, A., Kyberd, P.J., Chappell, P.H., Light, C.M., 2004. Marker placement to describe the wrist movements during activities of daily living in cyclical tasks. Clin. Biomech. 19, 248-254. https://doi.org/10.1016/j.clinbiomech.2003.11.012 
Padmore, C., Langohr, G.D., Suh, N., Johnson, J.A., 2020. The effect of coordinate system selection on wrist kinematics. J. Biomech. 109, 109881.

https://doi.org/10.1016/j.jbiomech.2020.109881

Reissner, L., Fischer, G., List, R., Taylor, W., Giovanoli, P., Calcagni, M., 2019. Minimal detectable difference of the finger and wrist range of motion: comparison of goniometry and 3D motion analysis. J. Orthop. Surg. 14. https://doi.org/10.1186/s13018-019-1177-y

Schwartz, C., Fedrigo, T., Brüls, O., Cescotto, S., Denoël, V., Croisier, J.-L., Forthomme, B., 2011. Reproducibility and repeatability of upper limb landmarks palpation for junior operators. Presented at the Proceedings of the XXIIIth Congress of the ISB. Brussels. http://isbweb.org/images/conf/2011/ScientificProgram/ISB2011_ScientificProgram_files/10 91.pdf

Wu, G., Siegler, S., Allard, P., Kirtley, C., Leardini, A., Rosenbaum, D., Whittle, M., D'Lima, D.D., Cristofolini, L., Witte, H., Schmid, O., Stokes, I., 2002. ISB recommendation on definitions of joint coordinate system of various joints for the reporting of human joint motion - part I: ankle, hip, and spine. J. Biomech. 35, 543-548.

https://doi.org/10.1016/S0021-9290(01)00222-6

Wu, G., van der Helm, F.C.T., Veeger, H.E.J., Makhsous, M., Van Roy, P., Anglin, C., Nagels, J., Karduna, A.R., McQuade, K., Wang, X., Werner, F.W., Buchholz, B., 2005. ISB recommendation on definitions of joint coordinate systems of various joints for the reporting of human joint motion-Part II: shoulder, elbow, wrist and hand. J. Biomech. 38, 981-992. https://doi.org/10.1016/j.jbiomech.2004.05.042 